SAKAI SAMBAYAN — Jurnal Pengabdian kepada Masyarakat

\title{
MENINGKATKAN POLA PANGAN HARAPAN MASYARAKAT DESA BETUNG MELALUI PEMBERDAYAAN MASYARAKAT
}

\author{
Yulistiati Nengsih", Rudi Hartawan, Ridawati Marpaung \\ Program Studi Agroteknologi Fakultas Pertanian Universitas Batanghari \\ Jl. Slamet Riyadi, Broni Jambi 36136 \\ Penulis Korespodensi : nyulistiati@yahoo.com
}

\begin{abstract}
Abstrak
Pola konsumsi pangan desa-desa di Muaro Jambi terdapat ketimpangan.Pemanfaatan sumber pangan lokal seperti umbi, jagung dan sayuran masih rendah.Pengembangan konsep rumah pangan lestari di Desa Betung perlu dilakukan. Beberapa permasalahan hasil identifikasi awal yang menyebabkan rendahnya pemanfaatan sumber daya lokal dan sayuran oleh ibu-ibu rumah tangga di Desa Betung adalah: Dasa Wisma dan Kelompok wanita Tani (KWT) tidak akrif, tidak ada pemanfaatan pekarangan, dan nilai pola pangan harapan (PPH) yang rendah. Tujuan yang ingin dicapai dalam kegiatan pengabdian kepada masyarakat ini adalah masyarakat aktif melaksanakan konsep RPL, mengurangi pengeluaran rumah tangga, dan meningkatkan skor PPH. Kegiatan pengabdian kepada masyarakat dilaksanakan di RT 06 dan RT 07 Desa Betung. Organisasi masyarakat yang menjadi target adalah kelompok Dasa Wisma dan KWT. Pelaksanaan pengabdian pada Bulan Januari sampai Oktober 2018. Kegiatan pemberdayaan masyarakat berupa: pengaktifan kembali Dasa Wisma dan KWT, pembuatan Kebun Bibit Desa, Kebun Demplot, Rumah Kompos, dan Rumah Pangan Lestari. Kegiatan pemberdayaan dievaluasi untuk mengetahui dampak ekonomi, nilai PPH, dan persepsi kooperator terhadap kegiatan yang dilaksanakan. Selama masa pengabdian, masyarakat aktif mengikuti penyuluhan dan diskusi serta kegiatan yang dilaksanakan. Hasil evaluasi menunjukkan bahwa terjadi penghematan pengeluaran rumah tangga sebesar Rp. 150.000 sampai Rp. 200.000, peningkatan nilai PPH dari 78,5 menjadi 82,09, serta persepsi yang sangat setuju terhadap kegiatan pengabdian yang dilaksanakan.
\end{abstract}

Kata kunci: Ketahanan pangan, RPL, pemberdayaan masyarakat

\section{Pendahuluan}

Pangan merupakan kebutuhan hak azazi manusia dimana kebutuhan pemenuhannya bagi setiap individu dijamin oleh Undang-undang Nomor 18 Tahun 2012 tentang pangan. Menurut Badan Ketahanan Pangan (2014) dan Suryana (2014), pangan merupakan segala sesuatu yang berasal dari sumber hayati dan air, baik yang diolah, yang diperuntukkan sebagai makanan atau minuman bagi konsumsi manusia, termasuk bahan tambahan pangan, bahan baku pangan, dan bahan lain yang digunakan dalam proses penyiapan, pengolahan dan atau pembuatan makanan atau minuman. Berdasarkan Peraturan Pemerintah Nomor 17 Tahun 2015 tentang ketahanan pangan dan gizi pada pasal 26 bahwa upaya penganekaragaman pangan salah satunya dilakukan melalui pemanfaatan lahan pekarangan.

Prinsip pemanfaatan pekarangan yang ramah lingkungan dan dirancang untuk pemenuhan kebutuhan pangan dan gizi keluarga, diversifikasi pangan berbasis sumber daya lokal, pelestarian tanaman pangan untuk masa depan, serta peningkatan pendapatan yang pada akhirnya akan meningkatkan kesejahteraan masyarakat. Konsep pemanfaatan lahan pekarangan seperti ini dikenal dengan rumah pangan lestari (RPL) (Balitbangtan Kementerian Pertanian, 2012). Menurut Mardiharini, Kariyasa, Zakiah, Dalmadi, Susakti (2011), untuk menjaga keberlanjutannya, pemanfaatan pekarangan dalam konsep Model RPL dilengkapi dengan kelembagaan kebun bibit desa, rumah kompos untuk pembuatan pupuk organik secara mandiri, dan pengetahuan pemasaran untuk memasarkan hasil yang melimpah. Jadi inti dari RPL adalah pemanfaatan pekarangan untuk pangan berupa tanaman sayuran, toga dan umbi-umbian. Menurut Astuti, Yanti dan Wahyuni (2013), pemilihan jenis komoditi haruslah disesuaikan dengan kebutuhan lingkungan tanaman dan disukai oleh masyarakat. Ditambahkan oleh Sarwo Aji dan Sholihah (2016) bahwa RPL dapat menurunkan pengeluaran rumah tangga. Hasil penelitiannya di Desa Puncangsari Kecamatan Purwodadi 
Kabupaten Pasuruan menunjukkan bahwa pengeluaran rumah tangga peserta RPL menurun Rp 200.000 sampai Rp 300.000 per bulan karena adanya pemenuhan pangan dari pekarangan sendiri. Hal yang sama juga didapat oleh Saputra, Putra dan Suardi (2016) di kelompok wanita tani (KWT) Tunas Sejahtera di Kecamatan Blahbatuh, Kabupaten Gianyar. Beberapa tanaman yang umum ditanam di pekarangan adalah sayuran, tanaman obat keluarga dan palawija dan umbi-umbian.

Pengembangan RPL sangat penting untuk meningkatkan skor pola pangan harapan $(\mathrm{PPH})$ dan diversifikasi pangan di sebuah desa (Rizal dan Fiana, 2015). Pola konsumsi pangan desa-desa di Muaro Jambi terdapat ketimpangan. Pemanfaatan sumber pangan lokal seperti umbi, jagung dan sayuran masih rendah. Pengembangan konsep RPL di desa-desa perlu dilakukan untuk meningkatkan PPH. Desa yang menjadi target dalam kegiatan pengabdian ini adalah Desa Betung.

Desa Betung yang terletak di Kecamatan Kumpeh Kabupaten Muaro Jambi. Secara geografis, Desa Betung mempunyai batas wilayah sebagai berikut; sebelah Barat berbatas dengan Desa Mekarsari, sebelah Timur berbatas dengan Desa Pulau Mentaro, sebelah Utara berbatasan dengan Desa Puding dan sebelah Selatan berbatasan dengan Desa Pematang Raman. Pada tahun 2015, jumlah penduduk Desa Betung mencapai 1.968 orang dengan 396 kepala keluarga. Sampai saat ini fasilitas pendidikan hanya sebatas sekolah dasar (Kecamatan Kumpeh Dalam Angka, 2016).

Desa Betung berbasis perkebunan.Tanaman perkebunan yang dominan adalah Kakao dan Kelapa Sawit dengan luasan masing-masing mencapai 695 dan 130.587.Umumnya masyarakat bermata pencaharian petani kakao atau buruh pada perkebunan kelapa sawit (Kecamatan Kumpeh dalam Angka, 2016). Dominasi yang besar dari tanaman perkebunan membuat hampir semua tenaga kerja tercurah ke sektor ini. Budidaya tanaman pangan dan pemanfaatan pekarangan hampir tidak ada sehingga menyebabkan skor pola pangan harapan tidak ideal dan diversifikasi pangan menjadi rendah.

Masyarakat Desa Betung yang menjadi target dalam kegaiatan ini adalah kelompok dasa wisma dan KWT. Dasa Wisma adalah kelompok ibu-ibu rumah tangga dari 10 keluarga yang bertanggungjawab terhadap jalannya sebuah program. Kelompok wanita tani adalah kaum perempuan secara langsung dalam usaha-usaha peningkatan hasil pertanian, seperti menjadi bagian dari motivator dalam adopsi dan pengenalan teknologi tani. Di Desa Betung, Dasa Wisma dan KWT tidak aktif. Kegiatan pengabdian ini bertujuan untuk memberdayaan ibu-ibu agar Dasa Wisma dan KWT kembali aktif dan menjadi bagian dari motivator dalam adopsi dan pengenalan teknologi budidaya dan pengolahan pangan untuk meningkatkan skor PPH.

\section{Bahan dan Metode}

Kegiatan pengabdian skema Program Kemitraan Masyarakat ini Dilaksanakan pada Bulan Pebruari sampai Oktober 2018 dan bertempat di RT 6 dan RT 7, Desa Betung, Kecamatan Kumpeh, Kabupaten Muaro Jambi. Kooperator dalam pelaksanaan pengabdian ini sebanyak 20 orang ibu rumah tangga yang juga sebagai anggota KWT Anggrek dan Dasa Wisma Mawar.

Bahan-bahan yang akan digunakan dalam kegiatan ini adalah benih sayuran (cabe keriting, bayam, kangkung, sawi, kacang panjang, selederi, tomat), bibit umbi-umbian (stek ubikayu varitas Barokah 1.000 batang dan stek ubijalar varitas Borobudur 1.000 batang), benih jagung manis dan jagung hibrida. Bibit empon-emponan (kunyit, jahe, dan lengkuas). Media tanam, polibag dan pupuk (urea $50 \mathrm{~kg}$, SP $3650 \mathrm{~kg}$ dan $\mathrm{KCl} 50 \mathrm{~kg}$ ). Pengendalian hama penyakit menggunakan agen hayati dan gulma secara manual. Peralatan yang digunakan adalah seperangakat alat pengolahan tanah (parang, cangkul dan traktor tangan), alat dokumentasi (kamera dan video). Seperangkat peralatan untuk penyuluhan (laptop, infocus, generator dan pengeras suara). Seperangkat papan merek dan spanduk kegiatan dan sperangkat alat tulis.Langkah kerja pengabdian dimulai dari pemberdayaan masyarakat dan diakhiri dengan evaluasi.

\section{A. Pemberdayaan Masyarakat \\ 1. Pengaktifan Kembali Dasa Wisma dan Kelompok Wanita Tani \\ Dasa wisma adalah sekelompok komunitas} ibu-ibu yang terdiri dari sepuluh keluarga atau sekelompok komunitas ibu-ibu dalam suatu RT, dibagi menurut letak geografis, utara, selatan, timur dan barat, atau pinggir kanan, tengah, dan pinggir kiri. Dasa Wisma Mawar dan KWT Anggrek terletak di RT 06 dan 07 di Desa Betung. Dasa 
Wisma dan KWT memiliki sumberaya yang cukup yaitu wanita usia produktif dan ada tokoh masyarakat yang diperkirakan dapat mengatur kedua organisasi tersebut.

Metode yang dilakukan dalam pengaktifan kembali Dasa Wisma dan KWT ini adalah dengan penyuluhan seperti yang dilakukan oleh Harnisah, Emma, Edy dan Honorisah (2016) di Kota Palembang Sumatera Selatan. Kegiatan penyuluhan ini dilakukan dengan cara mengundang anggota Dasa Wisma dan KWT. Penyuluhan yang bertahap diharapkan dapat memotivasi anggota Dasa Wisma dan KWT untuk kembali aktif dalam menjalankan organisasi ini.

\section{Penyuluhan RPL dan Ketahanan Pangan Rumah Tangga}

Penyuluhan kedua ini dilaksanakan setelah

Dasa Wisma dan KWT tersebut telah diaktifkan kembali dan masing-masing anggota dapat memahami fungsi dan tugas pokoknya. Anggota Dasa Wisma dan KWT diberikan penyuluhan tentang ketahanan pangan rumah tangga serta upaya yang dapat dilakukan oleh ibu-ibu rumah tangga dalam memanfaatkan pekarangan rumah untuk menghasilkan bahan pangan. Dalam penyuluhan ini juga diberikan materi jenis-jenis tanaman dan ternak serta teknik budidaya agar tanaman dan ternak tersebut tumbuh dengan baik.

\section{Pembangunan Kebun Bibit Desa dan Rumah Kompos}

Kebun Bibit Desa merupakan tempat pelaksanaan pembibitan tanaman yang akan ditanam di pekarangan. Penyemaian dilakukan pada kotak-kotak persemaian dan polibag kecil.Kebun Bibit Desa berbentuk rumah bayang dengan atap dari shading net. Rumah kompos merupakan tempat pembuatan kompos yang produknya digunakan dalam kegiatan pembangunan rumah pangan lestari.Kebun Bibit dan rumah kompos dikelola oleh KWT. Untuk tanaman jagung, ubikayu dan ubijalar, langsung ditanam di lapangan.

\section{Pembangunan RPL}

Dari beberapa kajian yang dilakukan tim teknis KRPL Kementerian Pertanian, ternyata diperoleh 3 strata pekarangan rumah tangga dalam kawasan contoh di Indonesia (Balitbang Kementerian Pertanian, 2012) yaitu: strata 1, berpekarangan sempit $<100 \mathrm{~m} 2$, atau tanpa pekarangan, hanya ada teras, strata 2, berpekarangan sedang 100-300 m2, dan strata 3 berpekarangan luas $>300 \mathrm{~m} 2$.

Berdasarkan hasil tersebut, maka rancangan pemanfaatan lahan pekarangan juga disesuaikan dengan ketersediaan lahan yang terbagi dalam 3 kelas tersebut yaitu sempit, sedang dan luas.Sedangkan pola pengembangannya terdiri dari 4 kegiatan besar yaitu pola vertikultur dantanaman pot, bedengan sempit, bedengan luas, dan intensifikasi jalan/rumah ibadah. Khusus untuk pekarangan luas (strata 3), pemanfataannya ditambahkan kandang ternak ayam buras dan kolam ikan air tawar (nila atau mujaer). Berdasarkan hasil pengamatan awal, umumya luas pekarangan tertinggi kurang dari $100 \mathrm{~m} 2$. Dengan demikian RPL diarahkan pada strata 1.Kooperator yang memiliki halaman strata 3, selain pemanfaatan pekarangan juga diarahkan untuk memelihara ikan dan ternak ayam.

\section{B. Evaluasi}

Objek pengumpulan data adalah kooperator kegiatan pengabdian. Jumlah kooperator sebanyak 20 orang dan semuanya dijadikan sumber data primer. Data primer yang dikumpulkan adalah PPH awal, PPH akhir, jumlah pengeluaran keluarga untuk memenuhi kebutuhan pangan setiap hari, serta persepsi kooperator terhadap kegiatan yang dilaksanakan. Data sekunder berupa PPH nasional dan lain yang terkait dengan pelaksanaan pengabdian.

Kuisioner PPH diadopsi dari buku Pedoman Analisis Konsumsi Pangan Mandiri di Wilayah P2KP (Badan Ketahanan Pangan, 2014). Data yang dihimpun dari kuisioner tersebut adalah data susunan anggota rumah tangga, konsumsi pangan rumah tangga, dan frekuensi konsumsi pangan rumah tangga. Bersamaan dengan pengumpulan data $\mathrm{PPH}$ setelah pelaksanaan kegiatan, juga dilakukan pengumpulan data tentang jumlah pengeluaran keluarga untuk memenuhi kebutuhan pangan setiap hari, serta persepsi kooperator terhadap kegiatan yang dilaksanakan.

Respon kooperator dalam pelaksanaan kegiatan yang bertujuan meningkatkan pola pangan harapan dilakukan dengan diskusi dan tanya jawab untuk setiap kegiatan yang dilakukan. Komponen yang disiskusikan dengan kooperator adalah pengaktifan KWT, pengaktifan Dasa Wisma, penggunaan benih bermutu, pembangunan kebun bibit desa, pembangunan rumah kompos, 
pembangunan rumah demplot, dan pembangunan rumah pangan lestari. Tanggapan dan persepsi diberi skor 1 sampai 5. Semakin tinggi skor, maka semakin baik respon kooperator terhadap kegiatan yang dilaksanakan. Hasil skoring dilanjutkan dengan analisis Likert (1932) dengan rumus sebagai berikut: Skor $=\frac{\sum \text { bn } \mathrm{n} n}{\mathrm{~N}}$, dimana skor minimal 1 dan maksimal 5; $\sum$ bn $=$ jumlah kooperator yang memberi pernyataan; bn= bobot skor: $1=$ tidak setuju, $2=$ setuju, $3=$ agak setuju, $4=$ setuju, dan $5=$ sangat setuju.

\section{Hasil dan Pembahasan}

Pelaksanaan pengabdian masyarakat dengan skema PKM telah menghasilkan beberapa kegiatan yang diharapkan dapat berkelanjutan dalam membangun RPL di Desa Betung Kabupaten Muaro Jambi. Beberapa indikator telah menunjukkan hasil pengabdian mengarah ke jalur yang telah direncanakan. Tabulasi rencana dan realisasi disajikan sebagai berikut:

Tabel 1. Status indikator sebelum dan setelah kegiatan pengabdian masyarakat skema PKM di Desa Betung Kabupaten Muaro Jambi

\begin{tabular}{|l|l|l|l|}
\hline No. & Indikator & $\begin{array}{l}\text { Sebelum } \\
\text { Pelaksanaan }\end{array}$ & $\begin{array}{l}\text { Setelah } \\
\text { Pelaksanaan }\end{array}$ \\
\hline 1. & Dasa Wisma & Pasif & Aktif \\
\hline 2. & Kebun Bibit Desa & Tidak ada & Ada \\
\hline 3. & Kelompok Wanita Tani & Pasif & Aktif \\
\hline 4. & Pengolahan pangan rumah tangga & Pasif & Aktif \\
\hline 5. & Kerjasama dengan instansi terkait & Tidak ada & Ada \\
\hline 6. & Pola Pangan Harapan & 78,5 & 82,09 \\
\hline 7. & Penyuluhan terintegrasi & Tidak ada & Ada \\
\hline 8. & $\begin{array}{l}\text { Dampak Ekonomi (penghematan pengeluaran pangan } \\
\text { rumah tangga, Rp per bulan) }\end{array}$ & Tidak ada & Ada (Rp. 150.000) \\
\hline
\end{tabular}

Tabel 1 menggambarkan status indikator setelah dilaksanakan kegiatan pengabdian kepada masyarakat. Beberapa kegiatan yang semula tidak ada menjadi ada dan yang pasif menjadi aktif. Demikian pula dengan $\mathrm{PPH}$, sebelumnya masih bernilai 78,5 dan setelah pelaksanaan pengabdian menjadi 82,09 . Beberapa kegiatan lain yang juga sangat bernilai adalah terjalinnya kerjasama dengan institusi yaitu Balai Benih Induk Hortikultura Provinsi Jambi dan adanya penyuluhan terintegrasi sesuai permintaan masyarakat. Kegiatan ini diawali dengan pemberdayaan masyarakat lalu dilanjutkan dengan evaluasi untuk mengetahui dampak kegiatan pengabdian ini.

\section{A. Pemberdayaan Masyarakat}

Dasa Wisma Mawar dan KWT Anggrek yang berada di RT 06 dan 07 Desa Betung telah diaktifkan kembali melalui kegiatan pengabdian kepada masyarakat ini. Ibu-ibu rumah tangga anggota dimotivasi melalui beberapa kegiatan penyuluhan. Karakteristik anggota dasa wisma dan kelompok wanita tani yang dijadikan kooperator disajikan pada Tabel 2.

Tabel 2. Karakteristik kooperator kegiatan pengabdian kepada masyarakat di Desa Betung, Kecamatan Kumpeh, Kabupaten Muaro Jambi

\begin{tabular}{|l|l|l|l|l|l|l|}
\hline No. & Nama & $\begin{array}{l}\text { Jumlah } \\
\text { Anggota } \\
\text { Keluarga }\end{array}$ & Alamat & Pendidikan & $\begin{array}{l}\text { Umur } \\
(\mathrm{Th})\end{array}$ & Pekerjaan \\
\hline 1. & Wardiati & 4 & RT. 06 & SD & 50 & IRT/Tani \\
\hline 2. & Wardah & 3 & RT. 06 & SD & 47 & IRT/Tani \\
\hline 3. & Rukiah & 4 & RT. 06 & SLTA & 46 & Honorer/Tani \\
\hline 4. & Zubaidah & 5 & RT. 06 & SD & 43 & IRT/Tani \\
\hline 5. & Zuhriah & 4 & RT. 06 & SD & 29 & IRT/Tani \\
\hline 6. & Zahrah & 3 & RT. 06 & SD & 34 & IRT/Tani \\
\hline
\end{tabular}




\begin{tabular}{|l|l|l|l|l|l|l|}
\hline 7. & Sa'adah & 4 & RT. 06 & SD & 58 & IRT/Tani \\
\hline 8. & Eli Rahmawati & 5 & RT. 06 & SD & 24 & IRT/Tani \\
\hline 9. & Hamisah & 5 & RT. 06 & SLTP & 31 & IRT/Tani \\
\hline 10. & Yusmerni & 4 & RT. 06 & SD & 41 & IRT/Tani \\
\hline 11. & Zairatul & 4 & RT. 06 & SLTP & 46 & Dagang/Tani \\
\hline 12. & Eni Yurna & 4 & RT. 07 & SD & 37 & IRT/Tani \\
\hline 13. & Siti Ami & 5 & RT. 07 & SD & 55 & IRT/Tani \\
\hline 14. & Sukainah & 4 & RT. 07 & SLTP & 43 & IRT/Tani \\
\hline 15. & Hartati & 5 & RT. 07 & SD & 42 & IRT/Tani \\
\hline 16. & Haryati & 3 & RT. 07 & SLTA & 27 & IRT/Tani \\
\hline 17. & Nurlaila & 4 & RT. 07 & SD & 53 & IRT/Tani \\
\hline 18. & Murbiah & 3 & RT. 07 & SD & 37 & IRT/Tani \\
\hline 19. & Erni & 3 & RT. 07 & SLTP & 37 & IRT/Tani \\
\hline 20. & Rahmi & 3 & RT. 07 & SD & 32 & IRT/Tani \\
\hline
\end{tabular}

Sumber: Data Primer

Tabel 2 menginformasikan bahwa dari 70\% kooperator yang berpendidikan SD 30\%, SLTP 25\%, dan SLTA 5\%. Penyuluhan bertahap merupakan strategi yang dilakukan tim pengabdian mengingat tingkat pendidikan kooperator yang rendah. Semua kooperator adalah ibu rumah tangga yang juga merangkap sebagai petani.Usia berkisar antara 24 sampai 55 tahun dengan kondisi kesehatan yang cukup baik untuk melaksanakan aktivitas sehari-hari.

Kegiatan pemberdayaan masyarakat diawali dengan pembangunan KBD dan rumah kompos. Keberadaan KBD sangat penting untuk menyediakan bibit yang akan ditanam oleh anggota. Kegiatan KBD dikoordinir langsung oleh Ketua KWT Anggrek. Kebun bibit desa menyediakan bibit sayuran yang telah disemai. Pada awal kegiatan ini masyarakat dapat memperoleh bibit sayuran secara gratis, namun diharapkan setelah kegiatan ini berakhir, maka diharapkan KBD dapat mandiri dengan cara menjual bibit sayuran yang dibutuhkan oleh masyarakat.

Pembuatan kompos dari bahan sisa rumah tangga dilakukan di rumah kompos.Kegiatan ini juga dikoordinir oleh Ketua KWT. Bahan-bahan kompos adalah kulit buah kakao, sampah rumah tangga, kotoran sapi dan EM4. Pengomposan dilakukan dengan metode wind row system seperti yang dilakukan oleh Hartawan, Nengsih, dan Marwan (2017) sebagai berikut: sampah rumah tangga dan kulit buah kakao terlebih dahulu disusun dan diatasnya ditaburkan kotoran sapi. Tinggi tumpukan $0,75 \mathrm{~m}$ dan lebar tumpukan $2 \mathrm{~m}$.
Larutan EM4 disiramkan pada tumpukan bahan kompos. Selanjutnya tumpakan bahan ditutup dengan plastik. Pengadukan dilakukan secara berkala setiap 15 hari.

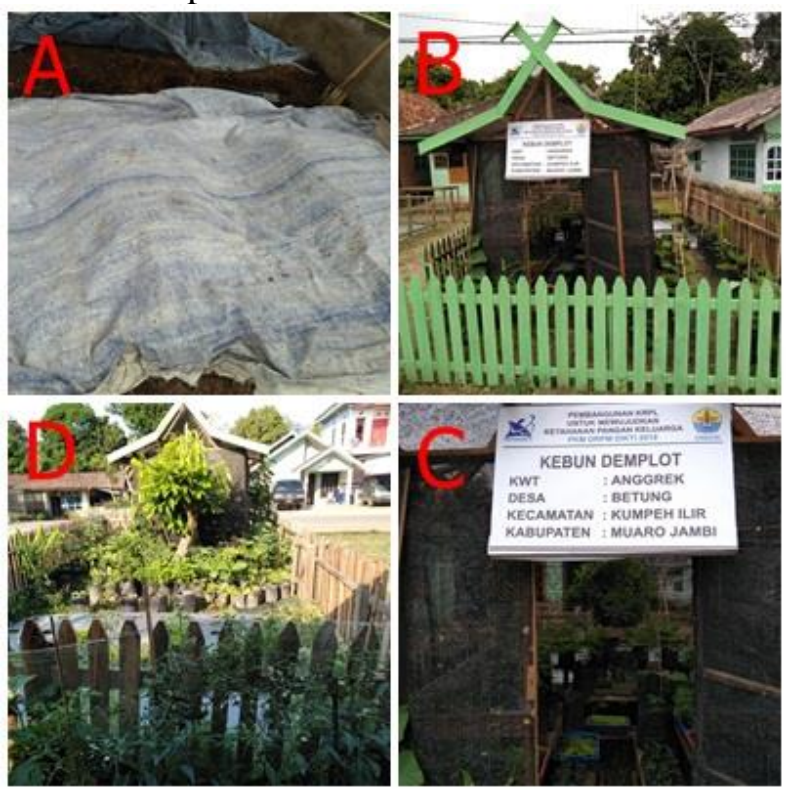

Gambar 1. Pemberdayaan anggota Dasa Wisma dan KWT dalam membangun rumah kompos (A), Kebun demplot (B), kebun demplot (C), dan pekarangan (D)

Bibit sayuran yang telah disemaikan, media tanam dan polibag diberikan kepada kooperator. Setiap anggota mendapat bibit cabe, tomat, seledri, kemangi, sawi, terong, jahe, kunyit, lengkuas dan kencur masing-masing 5 polibag. Kooperator juga mendapat bibit ubikayu, ubijalar, dan jagung manis. Anggota yang memiliki pekarangan luas mendapat bantuan ternak ikan dan ayam. Kegiatan 
ini juga menyiapkan satu unit kebun demplot yang bertujuan untuk menginspirasi kooperator.

Budidaya pekarangan merupakan fokus utama kegiatan ini. Kegiatan tambahan lain yang tidak kalah pentingnya adalah pengolahan bahan pangan hasil panen di pekarangan masyarakat. Kegiatan penyuluhan berupa pembuatan saos tomat dan abon ikan telah dilakukan dan diikuti oleh ibuibu dengan sangat antusias. Demikian juga dengan pembuatan coklat dari buah kakao hasil panen dari kebun masyarakat juga diikuti dengan suka cita.

Kegiatan penyuluhan tambahan dilakukan sesuai dengan permintaan dari masyarakat Desa Betung. Pada kegiatan ini dilakukan penyuluhan tentang pengendalian hama dan penyakit tanaman kakao yang di sampaikan oleh dosen yang memiliki kompetensi di bidang hama penyakit tanaman yaitu Bapak. Drs. H. Hayata,MP dan Ibu Ir. Yuza Defitri MP, yang khusus di undang oleh pelaksana.

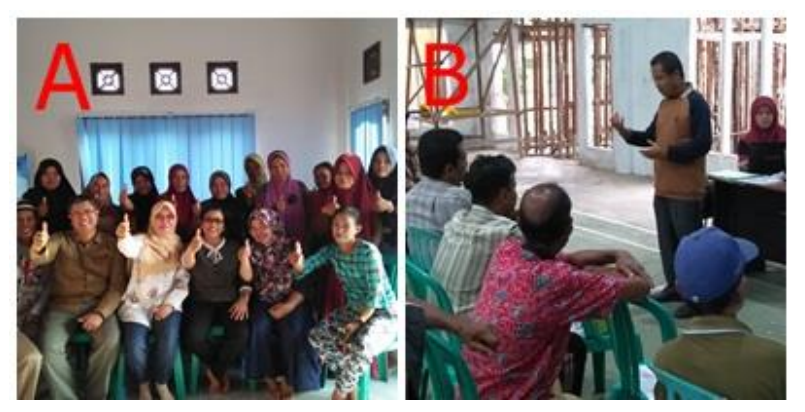

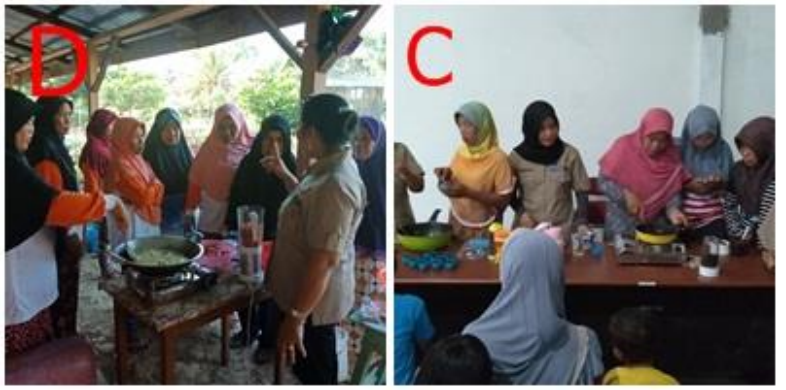

Gambar 2. Kegiatan penyuluhan terintegrasi mengenai : Dasa Wisma dan KWT (A), hama dan penyakit tanaman (B), pengolahan kakao (C) dan pembuatan saos tomat dan abon ikan (D)

Kegiatan penyuluhan pengaktifan kembali Dasa Wisma dan KWT, pembuatan coklat, saos tomat dan abon ikan diikuti oleh ibu-ibu rumah tangga di RT 06 dan 07. Penyuluhan hama dan penyakit diikuti oleh Bapak dan Ibu yang ada di RT 06 dan 07. Masyarakat dan kooperator sangat antusias mendapatkan ilmu dari tim penyuluh. Selama masa pengabdian, tercatat ada 6 kali penyuluhan yang dilaksanakan. Strategi penyuluhan yang berulang ini dengan harapan kooperator dapat menyerap ilmu yang disampaikan.

Kerjasama dengan Balai Benih Induk Hortikultura (BBI Horti) Provinsi Jambi merupakan kegiatan penting dalam kegiatan pengabdian kepada masyarakat. Kerjasama Tim Pelaksana Pengabdian dengan BBI Hortikultura berupa penyaluran bibit unggul buah-buahan dan bibit cabe merah dilaksanakan tanggal 12 April 2018. Jenis dan jumlah bibit yang disalurkan disajikan pada Tabel 3 berikut.

Tabel 3. Jenis dan jumlah bibit yang disalurkan kepada masyarakat Desa Betung hasil kerjasama Tim Pelaksana Pengabdian dengen BBI Horti Provinsi Jambi

\begin{tabular}{|l|l|l|l|}
\hline No. & Jenis Bibit & $\begin{array}{l}\text { Jumlah } \\
(\text { Polibag })\end{array}$ & Penerima \\
\hline 1. & Cabe Merah umur 14 Hari & 200 & Kooperator Pelaksanaan Pengabdian \\
\hline 2. & Durian Monthong & 180 & Masyarakat Desa Betung \\
\hline 3. & Sawo Manila & 20 & Kooperator Pelaksanaan Pengabdian \\
\hline 4. & Jambu Putih & 20 & Kooperator Pelaksanaan Pengabdian \\
\hline 5. & Duku & 20 & Kooperator Pelaksanaan Pengabdian \\
\hline 6. & Lengkeng & 20 & Kooperator Pelaksanaan Pengabdian \\
\hline
\end{tabular}

Bibit Durian, Sawo Manila, dan Jambu Putih merupakan bibit dengan kelas Label Ungu. Penyerahan bibit dengan Label Ungu tersebut mempunyai tujuan tersendiri. Kepala BBI
Hortikultura Provinsi Jambi berharap para pemuda Desa Betung dapat menjadi penangkar bibit tersebut.Tanaman buah dapat diperbanyak secara generatif dengan okulasi. Kegiatan pelatihan 
perbanyakan secara generatif (perbanyakan klon) merupakan salah satu komitmen yang dibuat dalam kerjasama antara Tim Pelaksana Pengabdian dengan Kepala BBI Horti Provinsi Jambi.

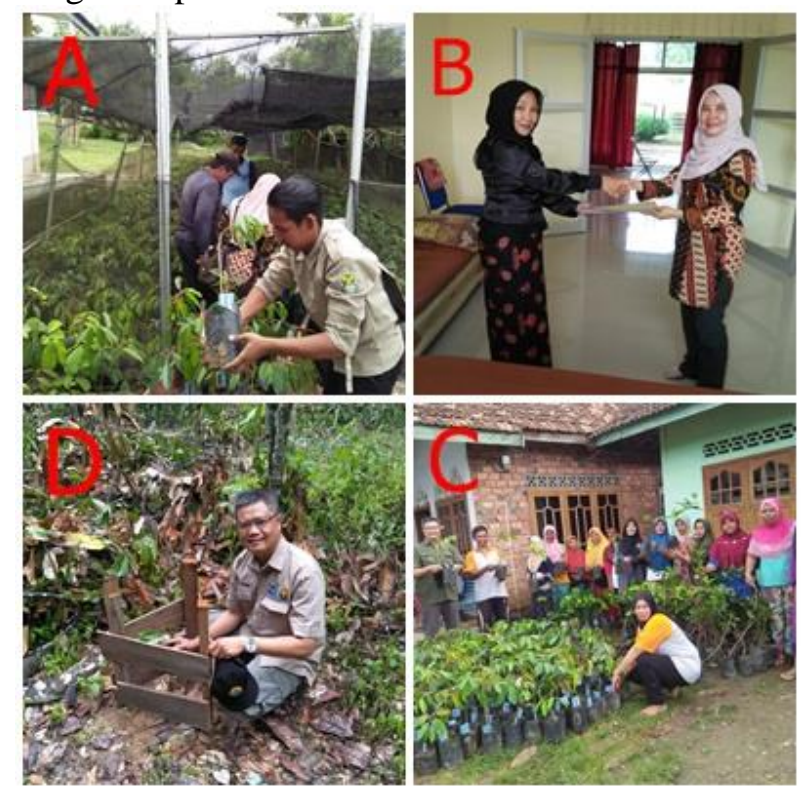

Gambar 3. Kerjasama tim pengabdian dengan BBI Hortikultura Provinsi Jambi dalam penyaluran bibit tanaman buah. (A) pengangkutan bibit dari BBI Horti ke Desa Betung, (B) tanda terima dari Ketua BBI Horti kepada Ketua Pelaksana Pengabdian, (C) penyerahan bibit kepada masyarakat dan kooperator, dan (D) pengamatan pertumbuhan bibit di lapangan

Tim pelaksana pengabdian mengadakan penyuluhan tentang cara penanaman serta pemeliharaan yang baik. Pertumbuhan bibit tanaman dipantau dan mendiskusikan dengan masyarakat bila terdapat kendala-kendala di lapangan.

\section{B. Evaluasi}

1. Dampak Ekonomi

Kegiatan pemberdayaan masyarakat yang bertujuan untuk meningkatkan kesejahteraan dimulai dari dampak ekonomi kegiatan yang dilaksanakan. Hasil wawancara dengan 20 orang kooperator yang dilaksanakn bersamaan dengan pengamatan $\mathrm{PPH}$, rata-rata menyatakan bahwa mereka dapat menghemat uang belanja sekira Rp. 150.000,00 sampai Rp. 200.000,00.Penghematan ini didapat dari dari belanja sayuran, umbi-umbian, dan empon-emponan.Penghematan utama didapat dari kemampuan kooperator menyiapkan kebutuhan sayur-sayuran.Kegiatan ini juga diharapkan dapat meningatkan penghematan keluarga dari belanja umbi-umbian dan protein hewani, hanya saja sampai wawancara ini dilaksanakan, kooperator belum dapat memanen ikan dan ternak ayam yang dilaksanakan sebagai bagian dari kegiatan ini.

\section{Pola Pangan Harapan}

Ketahanan Pangan tercermin dari tersedianya pangan yang cukup Jumlah maupun mutunya, aman, beragam, bergizi, merata dan terjangkau. Ketersediaan pangan juga dapat disuplai dari pekarangan rumah masyarakat dengan cara pemberdayaan masyarakat melalui rumah pangan lestari. Salah satu output kegiatan pengabdian masyarakat di Desa Betung adalah meningkatkan status PPH. Data PPH dapat dijadikan dasar kecukupan gizi masyarakat. Berikut disajikan data PPH sebelum dan setelah dilaksanakan kegiatan.

Tabel 4. Pola pangan harapan di Desa Betung sebelum dan setelah dilaksanakan kegiatan pengabdian kepada masyarakat

\begin{tabular}{|l|l|r|r|r|}
\hline \multirow{2}{*}{ No. } & & \multicolumn{2}{|c|}{$\begin{array}{c}\text { Skor PPH } \\
\text { Nasional }\end{array}$} & \multicolumn{2}{|c|}{ Skor PPH Desa Betung } \\
\cline { 4 - 5 } & & 33,5 & 33,9 & \multicolumn{2}{c|}{ Setelah Kegiatan } \\
\hline 1. & Padi & 2,2 & 1,5 & 33,0 \\
\hline 2. & Umbi & 11,6 & 7,0 & 1,7 \\
\hline 3. & Hewani & 17,5 & 14,6 & 7,0 \\
\hline 4. & Minyak/ Lemak & 1,5 & 0,9 & 14,6 \\
\hline 5. & Buah/Biji & 7,6 & 4,1 & 1,2 \\
\hline 6. & Kacang & 1,5 & 1,2 & 4,1 \\
\hline 7. & Gula & & & 1,2 \\
\hline
\end{tabular}




\begin{tabular}{|l|l|r|r|r|}
8. & Sayur dan Buah & 24,7 & 15,0 & 29,4 \\
\hline 9. & Lain lain & 0,0 & 0,0 & 0,0 \\
\hline Total & 100,0 & 78,50 & 82,09 \\
\hline
\end{tabular}

Peningkatan nilai PPH di Desa Betung dari 78,50 menjadi 82,09 (naik sebesar 1,97\%) merupakan dampak positif dari kegiatan KRPL. Sebenarnya nilai 82,09 tersebut belumlah sebesar harapan di Provinsi Jambi sebesar 85,55 dan ratarata Provinsi Jambi sebesar 83,40. Menurut Anwar (2014) dan Pertiwi (2014), meningkatnya pengetahuan dan kesadaran masyarakat untuk mengkonsumsi makna beragam, bergizi, seimbang dan aman (B2SA), melalui pemberdayaan Dasa Wisma dan Kelompok Wanita Tani.

Berdasarkan Undang-Undang Nomor 18 Tahun 2012 tentang pangan, pemerintah bersama masyarakat bertanggung jawab mewujudkan ketahanan pangan, sekaligus mengimbau seluruh pemangku kepentingan untuk bersinergi mewujudkan ketahanan pangan. Penanganan ketahanan pangan ini juga telah diperkuat dengan piranti hukum dengan diterbitkannya PP No. 38 Tahun 2007 dan PP No. 41 Tahun 2017 yang dengan tegas menyatakan bahwa ketahanan pangan merupakan salah satu urusan wajib yang harus ditangani oleh daerah.

Peningkatan nilai PPH di Desa Betung yang diinisiasi dari pemanfaatan pekarangan melalui penanaman sayuran, umbi-umbian dan didorong juga oleh pemanfaatan pekarangan lainnya untuk budidaya ikan dan budidaya ayam buras. Dalam kegiatan ini, masyarakat kooperator yang memiliki kolam ikan dibantu dengan bibit ikan dan yang memiliki kandang ternak ayam diberi bantuan indukan dan anakan ayam. Menurut Ngaisah (2017), PPH sangat terkait dengan kejadian stunting pada baita dan kesehatan anak pada umumnya.

\section{Tanggapan dan Persepsi Kooperator}

Kegiatan pembangunan RPL di Desa Betung mendapat sambutan yang baik. Fakta bahwa kegiatan ini diminati dan diharapkan adalah tanggapan dan persepsi kooperator seperti yang disajikan pada Tabel 5 berikut.

Tabel 5. Tanggapan dan persepsi kooperator RPL di Desa Betung

\begin{tabular}{|l|l|l|l|l|l|l|r|}
\hline \multirow{2}{*}{ No. } & \multirow{2}{*}{ Komponen yang Dinilai } & \multicolumn{5}{l|}{ Tanggapan } & \multirow{2}{*}{ Skersepsi Kooperator } \\
\cline { 3 - 7 } & & SSt & St & ASt & KSt & TSt & \\
\hline 1. & Pengaktifan Kelompok Wanita Tani & 18 & 0 & 2 & 0 & 0 & 4,8 \\
\hline 2. & Pengaktifan Dasa Wisma & 20 & 0 & 0 & 0 & 0 & 5 \\
\hline 3. & Penggunaan Benih Bermutu & 18 & 2 & 0 & 0 & 0 & 4,9 \\
\hline 4. & Pembangunan Kebun Bibit Desa & 20 & 0 & 0 & 0 & 0 & 5 \\
\hline 5. & Pembangunan Rumah Demplot & 15 & 2 & 2 & 1 & 0 & 4,6 \\
\hline 6. & Pembangunan Rumah Kompos & 14 & 2 & 2 & 2 & 0 & 4,4 \\
\hline 8. & Pembangunan Rumah Pangan Lestari & 20 & 0 & 0 & 0 & 0 & 5 \\
\hline
\end{tabular}

Keterangan: $\mathrm{SSt}=$ sangat setuju, $\mathrm{St}=$ setuju, $\mathrm{ASt}=$ agak setuju, $\mathrm{KSt}=$ kurang setuju, $\mathrm{TSt}=$ tidak setuju

Tanggapan dan persepsi masyarakat sangat setuju dan setuju untuk kegiatan pengaktifan KWT, pengaktifan dasa wisma, penggunaan benih bermutu, pembangunan kebun bibit desa, pembangunan rumah demplot, pembnagunan rumah kompos, dan pembangunan rumah pangan lestari.Tanggapan dan persepsi yang baik ini mengindikasikan bahwa kegitan-kegiatan ini memang bermanfaat bagi kooperator. Manfaat yang didapat oleh kooperator adalah peningkatan skor PPH sebesar 4,57\% (dari 78,5 menjadi 82,09), penghematan belanja keluarga (Rp. 150.000,00 sampai Rp. 200.000,00), meningkatnya interaksi sosial karena dasa wisma dan KWT aktif kembali, serta ketersediaan kebun bibit desa dan rumah kompos yang memungkinkan pemanfaatan pekarangan dapat terus dilaksanakan.

\section{Kesimpulan dan Saran}

Hasil yang didapat dari kegiatan pengabdian kepada masyarakat dengan skema PKM adalah pengaktifan kembali Dasa Wisma dan KWT, 
terbentuknya kebun bibit desa, rumah kompos, rumah demlot, dan rumah pangan lestari. Dasa Wisma dan KWT menjadi motor penggerak dalam pelaksanaan kegiatan dan penyuluhan yang dilaksanakan oleh tim pelaksana pengabdian.

Hasil evaluasi kegiatan pengabdian masyarakat ini menunjukkan bahwa terjadi penghematan pengeluaran rumah tangga sebesar Rp. 150.000 sampai Rp. 200.000 per bulan, meningkatnya nilai PPH dari 79,5 menjadi 82,09. Kooperator sangat antusias dengan kegiatan yang dilaksanakan. Nilai persepsi menunjukkan skor $>4,5$ dalam skala 5. Persepsi yang sangat setuju ini menunjukkan bahwa kegiatan pengabdian masyarakat bermanfaat bagi kooperator warga RT 06 dan 07 Desa Betung, Kecamatan Kumpeh, Kabupaten Muaro Jambi.

Masyarakat diharapkan dapat terus melanjutkan kegiatan ini dengan memanfaatkan fasilitas yang telah tersedia dan berupaya melaksanakan kerjasama dengan perusahaan perkebunan yang di daerah tersebut.

\section{Ucapan Terima Kasih}

Ucapan terima kasih disampaikan kepada Bapak Direktur DRPM Dikti atas bantuan dana pengabdian skema PKM Tahun 2018 yang telah diberikan sehingga pengabdian ini dapat dilaksanakan. Terima kasih juga disampaikan kepada Bapak Rektor Universitas Batanghari atas bantuannya dalam pelaksanaan pengabdian ini

\section{Daftar Pustaka}

Anwar, K. 2014. Konsumsi pangan dan gizi serta skor pola pangan harapan. Jurnal Gizi dan Pangan. 9(1): $51-58$

Astuti H.B., A.Yanti. \& T.Wahyuni. 2013. Analisis Komoditas Pilihan Dalam Pemanfaatan Pekarangan Rumah Tangga di Kota Bengkulu. Prosiding Seminar Nasional Lahan Suboptimal 2013. Halaman 309-3013.

Biro Pusat Statistik Kabupaten Muaro Jambi. 2016. Kumpeh dalam Angka. BPS Kabupaten Muaro Jambi
Balitbangtan Kementerian Pertanian. 2012. KRPL di Maluku. Balitbangtan Kementerian Pertanian RI.

Badan Ketahanan Pangan. 2014. Peraturan Menteri Pertanian Republik Indonesia Nomor : 09/Permentan/Ot.140/1/2014 Tanggal : 27 Januari 2014 Pedoman Gerakan Percepatan Penganekaragaman Konsumsi Pangan Tahun 2014. Jakarta

Harnisah. S. Emma. I.K.W Edi dan B. Honorita. 2016. Kinerja Model Kawasan Rumah Pangan Lestari (M-KRPL) di Kota Palembang. Prosiding Seminar Nasional Lahan Suboptimal 2016.

Hartawan, R., Y. Nengsih., \& E. Marwan. 2017. Pemanfaatan serasah kedelai sebagai bahan kompos. Prosiding Seminar Nasional Politeknik Nengeri Lhokseumawe. Hal. 89-91.

Likert. R. 1932. A technique for the measurement of attitudes. Archives of Psychology.140: 1-55.

Mardiharini. K. Kariyasa. Zakiah.Dalmadi. A. Susakti. 2011. Petunjuk Pelaksanaan Pengembangan Model Kawasan Rumah Pangan Lestari. BBP2TP. Bogor.

Ngaisah, R.D. 2017. Keterkaitan Pola Pangan Harapan (PPH) dengan Kejadian Stunting Pada Balita. Jurnal Kedokteran dan Kesehatan. 13(1):71-79

Peraturan Pemerintah Nomor 17 Tahun 2015 tentang ketahanan pangan dan gizi

Pertiwi, K.L. 2014. Konsumsi pangan dan gizi serta skor pola pangan harapan. Jurnal Gizi dan Pangan. 9(2): $117-124$.

Rizal. H dan Y. Fiana. 2015. Teknologi budidaya tanaman sayuran dan TOGA di perkotaan danperdesaan pada kawasan rumah pangan lestari dalam mendukungketahanan pangan di Kalimantan Timur. Biodiversitas. 1(2): 324-329

Sarwo Aji. T. dan M. Sholihah. 2016. Dampak Program Kawasan Rumah Pangan Lestari (KRPL) Terhadap Pengeluaran Konsumsi Rumah Tangga. Laporan Penelitian. Fakultas Pertanian Universitas Yudharta Pasuruan

Suputra.I.G.N. I.G.S.A. Putra. I.D. P. O. Suardi. 2016. Evaluasi Dampak Program Kawasan Rumah Pangan Lestari (KRPL) pada Kelompok Wanita Tani (KWT) Tunas Sejahtera di Kecamatan Blahbatuh. Kabupaten Gianyar. E-Jurnal Agribisnis dan Agrowisata. 5 (1): 1-10

Suryana, A. 2014. Menuju Ketahanan Pangan Indonesia Berkelanjutan 2025: Tantangan dan Penanganannya. Jurnal Penelitian Agro Ekonomi. $\quad 32(2)$ 123-135. 